\title{
Uma análise do catálogo Arca do Gosto a partir da perspectiva dos jogos de linguagem de Wittgenstein
}

Un análisis del catálogo Arca del Gusto desde la perspectiva de los juegos del lenguaje de Ludwig Wittgenstein

An analysis of the Arca del Gusto catalogue from the perspective of Ludwig Wittgenstein's language-games

\section{Gabrieli Aparecida da FonseCA, Sonia TroItiÑo}

Departamento de Ciência da Informação, Faculdade de Filosofia e Ciências (UNESP-Marília), Av. Hygino Muzzi Filho, 737, Marilia - SP - Brasil, gabrieli.arq@gmail.com, sonia.troitino@unesp.br

\section{Resumen}

Se discute la presencia de los juegos del lenguaje en la construcción del catálogo Arca del Gusto, desde la perspectiva de Wittgenstein. El catálogo Arca del Gusto es un instrumento de organización del conocimiento desarrollado por el movimiento Slow Food, qué registra alimentos en peligro de extinción en todos los países donde el movimiento es activo. Esta reflexión se origina en el estudio de caso del registro de productos alimenticios brasileños. En cuanto a la metodología, se trata de una investigación exploratoria, con enfoque cualitativo, qué utiliza procedimientos bibliográficos y documentales, así como métodos de estudio de caso y análisis de dominio. El desarrollo del artículo se guía por el análisis de algunos alimentos del catálogo cuya identificación impregna el tema de los juegos del lenguaje, ya sea por la existencia de más de un producto con el mismo nombre, o porque un mismo alimento tenga varios nombres o, en ambos casos, simultáneamente. Se busca discutir brevemente los factores que conducen a la existencia de estos juegos del lenguaje, en el contexto de la cultura alimentaria brasileña y cuales alternativas la Organización del Conocimiento podrían aportar al catálogo Arca del Gusto, mientras sistema de organización del conocimiento. Como resultado, se identificó qué los juegos de lenguaje retratan la influencia de la cultura en la construcción de sistemas de organización del conocimiento, como el Arca del Gusto. También se constató la importancia social de la aplicación de estudios e instrumentos desarrollados en el campo de la Organización del Conocimiento para que las organizaciones desempeñen sus funciones con mayor éxito.

Palabras clave: Organización del conocimiento. Juegos del lenguaje. Arca del Gusto. Slow Food. Brasil.

\section{Introdução}

Este artigo pretende trazer uma análise do catálogo Arca do Gosto em relação às interações entre os jogos de linguagem tratados por Wittgenstein em seu "Livro Azul" e elementos da Organização do Conhecimento, tomando por base alguns produtos presentes no catálogo.

\begin{abstract}
This article seeks to discuss the presence of language games in the construction of the Ark of Taste catalog, from the perspective of Wittgenstein. The Ark of Taste catalog is an instrument for knowledge organization developed by the Slow Food movement, which registers food at risk of extinction in all countries where the movement is active. This reflection originates from the case study of the registry of Brazilian food products. Regarding he methodology, it is an exploratory research, with a qualitative approach, which uses bibliographic and documentary procedures, as well as methods of case study and domain analysis. Thus, the development of the article is guided by the analysis of some foods in the record whose identification permeates the issue of language games, whether due to the existence of more than one product with the same name, or due to the same food having several names or, in both cases, simultaneously. We seek to briefly discuss the factors that lead to the existence of these language games in the context of brazilian food culture and what alternatives related to the field of Knowledge Organization could contribute to the Ark of Taste catalog, as a system of knowledge organization. As a result, it was identified that language games portray the influence of culture in the construction of knowledge organization systems such as the Ark of Taste. It was also verified the social importance of the application of studies and instruments developed in the field of the Organization of Knowledge so that organizations perform their functions with greater success.
\end{abstract}

Keywords: Knowledge Organization. Language games. Ark of Taste. Slow food. Brazil.

A Arca do Gosto é um catálogo alimentar desenvolvido a partir da preocupação em se registrar alimentos que se encontram sob risco de extinção, para fins de preservação e conhecimento. Atualmente, essa iniciativa se encontra presente em aproximadamente 200 países, e tem como proposta registrar e proteger os produtos inseridos no catálogo (Irving e Ceriani, 2013). Trata-se de projeto vinculado ao Slow Food, movimento 
global de atuação local, criado em 1989 com a proposta de defender a alimentação de qualidade, valorizar a agricultura familiar, o meio ambiente e as tradições culinárias, conforme o Slow Food (2015).

O Slow Food é considerado um movimento social transdisciplinar, que discorre a respeito das diversas demandas relacionadas ao seu lema, que conforme (Makuta, 2018, p. 7) trata do "alimento bom, limpo e justo para todos". Dessa forma, o catálogo Arca do Gosto é igualmente transdisciplinar. García Marco (2021) lembra que, de igual modo, a Organização do Conhecimento é transdisciplinar em essência - o que destaca a importância da aplicação de técnicas da Organização do Conhecimento para melhor compreensão da Arca do Gosto em seu propósito.

O catálogo é construído de forma colaborativa, ou seja, os produtos registrados são indicados pela própria população através de um formulário disponível no site da Fundação Slow Food Internacional e submetidos à análise desta instituição antes de serem inseridos, a fim de verificar a veracidade das informações e relação com a cultura local.

Por se tratar de um dos principais projetos do Slow Food, a Arca do Gosto é sua base e, também, contribui para o desenvolvimento de outros projetos do movimento. Dessa forma, se aproxima muito da cultura local, tanto no que diz respeito à coleta e seleção de dados para construção de seu conteúdo, quanto no próprio fato de estar sempre muito próxima às comunidades locais - o que aproxima o projeto ainda mais da cultura local, como um todo.

Como catálogo, em sua concepção, a Arca do Gosto possui estreita relação com a linguagem e Organização do Conhecimento, inerentes à construção de instrumentos de registro. A forma como a linguagem é abordada na estrutura do catálogo está diretamente relacionada à sua capacidade de comunicação e transmissão de conhecimento sobre cultura alimentar ao público.

Para Wittgenstein (2012), no campo da linguagem, o significado de uma palavra é determinado pela variedade de usos - usos esses que estão permeados por questões culturais, como as variantes linguísticas regionais. A existência dessas variações permite problematizar a categorização de produtos proposta pela Arca do Gosto, no qual é possível encontrar ocorrências relacionadas à duplicação de um nome para diferentes produtos, assim como o emprego de diferentes nomes para um mesmo produto constata-se.

A partir dessa perspectiva, este artigo traz o levantamento e análise de elementos voltados à
Organização do Conhecimento, presentes na Arca do Gosto, como os nomes de produtos alimentares inseridos no catálogo e suas variações nominais determinadas a partir de fatores culturais.

Trata-se de uma pesquisa bibliográfica e documental, de natureza exploratória, abordagem qualitativa, a qual se vale dos métodos estudo de caso e análise de domínio para sua execução. Conforme dito anteriormente, esse artigo originase dos resultados da pesquisa "O papel da informação no resgate da cultura alimentar brasileira: uma análise do catálogo Arca do Gosto", a qual se encontra em desenvolvimento.

Desse modo, este artigo está estruturado da seguinte maneira: discussão a respeito das relações entre linguagem, mais especificamente no que diz respeito à teoria dos jogos de linguagem e Organização do Conhecimento, seguida de apresentação e reflexão de alguns exemplos de jogos de linguagem presentes no catálogo Arca do Gosto. Por fim, apresentam-se as considerações finais.

\section{Jogos de linguagem na Arca do Gosto}

A Arca do Gosto, que é um projeto do movimento Slow Food, presente em cerca de 200 países, e visa catalogar alimentos em risco de extinção no mundo todo. Seu processo de seleção se baseia em larga medida em critérios vinculados à cultura tradicional dos povos, em respeito aos recursos naturais e à diversidade que os caracteriza. Assim, o catálogo se organiza de forma local, de modo que cada país possui seu próprio repertório de alimentos catalogados. Aqui se trata do catálogo brasileiro, que atualmente conta com cerca de 200 itens registrados.

Nas palavras de Irving e Ceriani (2013, p. 30), a "Arca do Gosto registra a existência destes produtos, denuncia o risco de extinção, convida todos a fazerem alguma coisa para protegê-los". Faz parte de um projeto em escala mundial, desenvolvido a partir de estratégias bem definidas para o reconhecimento da carga cultural e econômica atreladas a biodiversidade de frutos e outros gêneros alimentícios locais. O projeto se preocupa com a identificação, levantamento histórico e nutricional, assim como com a organização e transmissão desse conhecimento, sempre em ação direta com a sociedade da qual derivam e em integração com a construção de um conhecimento maior.

Nesse sentido, a Arca do Gosto deve ser compreendida e analisada em conjunção com o próprio Slow Food, enquanto movimento global de 
atuação local em busca da preservação da cultura alimentar e da biodiversidade.

O fato do catálogo Arca do Gosto ser uma construção coletiva, para a qual qualquer pessoa pode indicar um produto específico (Makuta, 2018), estimula a refletir sobre a necessidade em se manter ou resgatar a produção e o consumo dos produtos registrados no catálogo. De certo modo, trata-se do reconhecimento de alimentos com forte significado para a cultura local. Os alimentos indicados passam por um processo de verificação das informações e pesquisa para maior detalhamento de suas características e significado para inserção no catálogo. Conforme Irving e Ceriani (2013), a indicação de produtos deve ser feita através do preenchimento de uma ficha disponível no site da Fundação Slow Food para a Biodiversidade (www.fondazioneslowfood.com), fundação vinculada ao movimento.

Dentre os critérios de inclusão dos produtos na Arca do Gosto, é importante destacar que estes devem estar relacionados à cultura local, artesanais e de qualidade especial, bem como estar em risco de extinção devido a ameaças a cultura e aos ecossistemas locais. Quanto às características dos produtos, estes podem ser variedades vegetais ou animais autóctones, espécies selvagens ou alimentos processados, conforme Serena Milano et al. (2013).

Para Hjorland e Albrechtsen (1995), uma das características relacionadas a um domínio é o vínculo em uma mesma esfera social, de modo que aqui compreende-se a Arca do Gosto como um domínio. Muito embora haja uma pluralidade em nossa cultura alimentar, pois ao descrever as características de produção, consumo e propriedades do alimento, a Arca do Gosto nos revela os vínculos associativos geográficos e humanos presentes na cultura alimentar, em relação a regiões, grupos ou território nacional. Assim, encontram-se na Arca alimentos relacionados a realidades regionais, inclusive com importante função socioambiental em seu contexto.

O campo da Organização do Conhecimento está relacionado entre outras coisas, com conceitos e suas relações semânticas, conforme Hjorland (2008), o que faz com que a abordagem dos jogos de linguagem nesse contexto seja bastante pertinente. A Arca do Gosto, enquanto sistema de organização do conhecimento tem a cultura como base e referência de sua construção, como os conceitos de seu sistema as próprias definições dos produtos nela inclusos.

Em sua concepção, a Arca do Gosto contempla as definições dos produtos registrados, segundo conceitos e usos cientificamente e culturalmente estabelecidos. Sendo assim, apresenta-se como um sistema de organização do conhecimento pautado na pesquisa histórica de tradições aliada ao conhecimento científico sobre a natureza e suas manifestações.

Desse modo, a reflexão aqui proposta, parte da literatura sobre os jogos de linguagem, concebidos por Ludwig Wittgenstein (2012). Com sua percepção da linguagem, enquanto elemento que se constrói a partir dos usos, Wittgenstein permite o estabelecimento de diversas relações entre as variações linguísticas presentes nos nomes que alguns produtos alimentares assumem. O caso brasileiro é bastante emblemático nesse sentido, em decorrência da grande diversidade cultural, mas, também, devido à riqueza em biodiversidade de sua fauna e flora. Muitas vezes as variações linguísticas ocorrem como forma de distinguir tipos ou cultivares distintos de um mesmo produto. Por sua vez, as ocorrências de inconsistências de comunicação reativas a itens da cultura alimentar local que apresentam variações linguísticas ou similaridade de nomenclatura com itens diferentes, é agravada pelo desconhecimento da própria cultura brasileira por parte dos brasileiros, o que destaca a relação entre cultura e sistemas de organização do conhecimento.

Nesse sentido, o pensamento de Wittgenstein faz refletir sobre as variações linguísticas existentes em relação aos produtos alimentares de nossa cultura serem reveladoras da cultura da qual estes fazem parte. Nesse passo, os jogos de linguagem de Wittgenstein podem se relacionar com a variação linguística que costuma ser assumida na grande parte dos produtos alimentares tradicionais, e que podem resultar em problemas conceituais e de compreensão, quando se trata de sistemas de organização do conhecimento voltados à cultura alimentar, como é o caso da Arca do Gosto.

Wittgenstein (2012) afirma ainda que não deve existir uma definição rigorosa das palavras, pois não há um uso único para cada palavra, mas vários usos. Assim, da mesma forma que para Wittgenstein (2012) as palavras não têm um uso único, variando conforme utilização nos jogos de linguagem, acreditamos que as palavras que se referem aos produtos alimentares selecionados para compor a Arca do Gosto, também são estabelecidas a partir de jogos de linguagem.

Nesse contexto, os jogos de linguagem se dão de três formas distintas: (1) quando o mesmo nome é atribuído a vários alimentos distintos; (2) quando um mesmo alimento assume nomes distintos; (3) quando as situações (1) e (2) ocorrem 
simultaneamente, conforme é pontuado com alguns exemplos expostos na Tabela I. A tabela em questão, é um excerto de uma outra tabela, mais abrangente, denominada Tabela Geral de Nomes de Produtos Alimentares Inseridos na
Arca do Gosto no Brasil, desenvolvida a partir da análise dos 200 alimentos registrados no Catálogo A Arca do Gosto no Brasil (Slow Food, 2017).

\begin{tabular}{|c|c|c|c|c|c|c|c|c|}
\hline $\begin{array}{l}\text { Termo } \\
\text { preferencial }\end{array}$ & $\begin{array}{l}\text { Nome } \\
\text { científico }\end{array}$ & $\begin{array}{l}\text { Variedade } \\
\text { de termos }\end{array}$ & Categoria & Região & Bioma & $\begin{array}{l}\text { Área de } \\
\text { produção }\end{array}$ & $\begin{array}{l}\text { Outros nomes } \\
\text { populares não } \\
\text { mencionados na arca }\end{array}$ & Observações \\
\hline $\begin{array}{l}\text { Arroz- } \\
\text { nativo-do- } \\
\text { pantanal }\end{array}$ & $\begin{array}{l}\text { Oryza latifolia } \\
\text { Desv; } \\
\text { Oryza } \\
\text { glumipatula } \\
\text { Steud. }\end{array}$ & $\begin{array}{l}\text { Arroz-do- } \\
\text { campo; } \\
\text { Machamo; }\end{array}$ & $\begin{array}{l}\text { Cereais e } \\
\text { farinhas }\end{array}$ & $\begin{array}{l}\text { Centro- } \\
\text { Oeste }\end{array}$ & Pantanal & $\begin{array}{l}\text { Barra do São } \\
\text { Lourenço e do } \\
\text { Castelo (Mato } \\
\text { Grosso do sul) }\end{array}$ & $\begin{array}{l}\text { Arroz vermelho; } \\
\text { arroz-vermelho- } \\
\text { nativo-do-pantanal; } \\
\text { arroz-vermelho-do- } \\
\text { pantanal; }\end{array}$ & $\begin{array}{l}\text { O arroz-nativo-do- } \\
\text { pantanal é um cultivar } \\
\text { nativo, e desde a chegada } \\
\text { dos colonizadores é } \\
\text { confundido com o arroz- } \\
\text { vermelho devido à sua } \\
\text { coloração, sendo } \\
\text { chamado também dessa } \\
\text { forma. }\end{array}$ \\
\hline $\begin{array}{l}\text { Arroz } \\
\text { vermelho }\end{array}$ & $\begin{array}{l}\text { Oryza sativa } \\
L .\end{array}$ & - & $\begin{array}{l}\text { Cereais e } \\
\text { farinhas }\end{array}$ & Nordeste & Caatinga & $\begin{array}{l}\text { Santana dos } \\
\text { Garrotes, } \\
\text { Vale do } \\
\text { Piancó } \\
\text { (Paraíba) }\end{array}$ & $\begin{array}{l}\text { Arroz vermelho da } \\
\text { Paraíba; Arroz } \\
\text { vermelho do Vale do } \\
\text { Piancó; }\end{array}$ & $\begin{array}{l}\text { Embora seja cultivado na } \\
\text { Caatinga, o arroz } \\
\text { vermelho é um cultivar } \\
\text { que foi inserido pelos } \\
\text { colonizadores. Devido à } \\
\text { similaridade da aparência, } \\
\text { o arroz vermelho costuma } \\
\text { ser muito confundido com } \\
\text { o arroz-nativo-do- } \\
\text { pantanal. }\end{array}$ \\
\hline Bacuri & $\begin{array}{l}\text { Scheelea } \\
\text { phalerata }\end{array}$ & $\begin{array}{l}\text { Acuri; } \\
\text { Ganguri; }\end{array}$ & $\begin{array}{l}\text { Frutas e } \\
\text { frutos secos }\end{array}$ & $\begin{array}{l}\text { Centro- } \\
\text { Oeste; } \\
\text { Nordeste; } \\
\text { Norte }\end{array}$ & $\begin{array}{l}\text { Cerrado; } \\
\text { amazônia }\end{array}$ & $\begin{array}{l}\text { Mato Grosso; } \\
\text { Mato Grosso } \\
\text { do Sul; Goiás }\end{array}$ & $\begin{array}{l}\text { Coco-acuri; auracuri; } \\
\text { guaracuri; }\end{array}$ & $\begin{array}{l}\text { Tanto o fruto cujo nome } \\
\text { mais popular é acuri } \\
\text { (cheelea phalerata) } \\
\text { quanto o cujo nome mais } \\
\text { popular é bacuri ( Platonia } \\
\text { insignis) são chamados } \\
\text { das duas formas, o que } \\
\text { contribuiu para uma } \\
\text { inconsistência no } \\
\text { catálogo, já que o termo } \\
\text { preferencial a ser utilizado } \\
\text { no mesmo deveria ser } \\
\text { acuri. }\end{array}$ \\
\hline Cambuí & $\begin{array}{l}\text { Myrciaria } \\
\text { tenella (DC.) } \\
\text { O. Berg }\end{array}$ & - & $\begin{array}{l}\text { Frutas e } \\
\text { frutos secos }\end{array}$ & $\begin{array}{l}\text { Nordeste; } \\
\text { Sudeste; } \\
\text { Sul }\end{array}$ & $\begin{array}{l}\text { Caatinga; } \\
\text { mata } \\
\text { atlântica }\end{array}$ & $\begin{array}{l}\text { Chapada de } \\
\text { Araripe e } \\
\text { Cariri } \\
\text { (Pernambuco } \\
\text { e Ceará) }\end{array}$ & $\begin{array}{l}\text { Cereja-de-Joinville; } \\
\text { cambuí-roxo; } \\
\text { camboí;camboim; } \\
\text { cambuí-preto; } \\
\text { murtinha; }\end{array}$ & $\begin{array}{l}\text { Um dos nomes populares } \\
\text { do cambuí é murtinha, } \\
\text { similar à como também é } \\
\text { conhecida a maria-preta } \\
\text { (que também costuma ser } \\
\text { chamada de murta, e até } \\
\text { mesmo de cambuí). }\end{array}$ \\
\hline Maria-preta & $\begin{array}{l}\text { Blepharocalyx } \\
\text { salicifolius } \\
\text { (Kunth) } \\
\text { O.Berg }\end{array}$ & $\begin{array}{l}\text { Murta; } \\
\text { Guamirim; } \\
\text { Cambuí }\end{array}$ & $\begin{array}{l}\text { Frutas e } \\
\text { frutos secos }\end{array}$ & $\begin{array}{l}\text { Centro- } \\
\text { Oeste; } \\
\text { Sudeste; } \\
\text { Sul }\end{array}$ & $\begin{array}{l}\text { Cerrado; } \\
\text { pantanal }\end{array}$ & $\begin{array}{l}\text { Mato Grosso; } \\
\text { Mato Grosso } \\
\text { do Sul }\end{array}$ & $\begin{array}{l}\text { Maria-pretinha; erva- } \\
\text { moura; erva-de-bicho; } \\
\text { erva-de-mocó; } \\
\text { guaraquinha; } \\
\text { pimenta; pimenta-de- } \\
\text { cachorro; pimenta-de- } \\
\text { rato; pimenta-de- } \\
\text { galinha e maria- } \\
\text { milagrosa; }\end{array}$ & $\begin{array}{l}\text { A maria-preta também } \\
\text { costuma ser chamada de } \\
\text { cambuí - nome que } \\
\text { também é utilizado para } \\
\text { se referir à pimenta-rosa e } \\
\text { à Myrciaria tenella (DC.) } \\
\text { O. Berg (à qual o nome } \\
\text { cambuí é mais popular). } \\
\text { As diversas variações } \\
\text { existentes ocasionam } \\
\text { muitos problemas } \\
\text { comunicacionais entre a } \\
\text { identidade dos três frutos } \\
\text { mencionados. }\end{array}$ \\
\hline $\begin{array}{l}\text { Ora-pro- } \\
\text { nóbis }\end{array}$ & $\begin{array}{l}\text { Pereskia } \\
\text { aculeata Mill. }\end{array}$ & $\begin{array}{l}\text { Trepadeira- } \\
\text { limão; } \\
\text { Carne-de- } \\
\text { pobre; } \\
\text { Groselha- } \\
\text { da-América }\end{array}$ & $\begin{array}{l}\text { Legumes, } \\
\text { verduras e } \\
\text { hortaliças }\end{array}$ & $\begin{array}{l}\text { Sudeste; } \\
\text { Norte; Sul }\end{array}$ & $\begin{array}{l}\text { Cerrado; } \\
\text { mata } \\
\text { alântica }\end{array}$ & $\begin{array}{l}\text { Arrarial de } \\
\text { Pompeu, } \\
\text { Município de } \\
\text { Sabará (Minas } \\
\text { Gerais) }\end{array}$ & $\begin{array}{l}\text { Lobrobró; guamacho; } \\
\text { mata-velha; jumbeba; } \\
\text { groselha-de-barbados }\end{array}$ & $\begin{array}{l}\text { Jumbeba é um nome } \\
\text { também atribuído ao } \\
\text { alimento (também inserido } \\
\text { no catálogo) cujo nome } \\
\text { mais popular é jurubeba }\end{array}$ \\
\hline $\begin{array}{l}\text { Pimenta } \\
\text { rosa }\end{array}$ & $\begin{array}{l}\text { Schinus } \\
\text { terebinthifolia } \\
\text { Raddi }\end{array}$ & $\begin{array}{l}\text { Aroeira; } \\
\text { Aguaraíba; } \\
\text { Cambuí, } \\
\text { Fruto-de- } \\
\text { Sabiá, } \\
\text { Coração-de- } \\
\text { Bugre) }\end{array}$ & $\begin{array}{l}\text { Condimentos } \\
\text { e especiarias }\end{array}$ & $\begin{array}{l}\text { Sudeste; } \\
\text { Centro- } \\
\text { Oeste; } \\
\text { Nordeste; } \\
\text { Sul }\end{array}$ & $\begin{array}{l}\text { Mata } \\
\text { attântica }\end{array}$ & Espírito Santo & $\begin{array}{l}\text { Aroeira-vermelha; } \\
\text { aroeira-da-praia; } \\
\text { corneiba; aroeira- } \\
\text { mansa; aroeira- } \\
\text { pimenteira; }\end{array}$ & $\begin{array}{l}\text { O fruto proveniente da } \\
\text { árvore mais conhecida } \\
\text { como aroeira, também é } \\
\text { chamado de cambuí - o } \\
\text { qual é o nome mais } \\
\text { popular da Myrciaria } \\
\text { tenella (DC.) O. Berg. }\end{array}$ \\
\hline
\end{tabular}

Tabela I. Tabela de Análise de Jogos de Linguagem na Arca do Gosto

A seleção dos alimentos para compor a Tabela 1 foi feita considerando os itens cujos termos apresentam jogos de linguagem que podem levar a ruídos de comunicação graves. Além disso, também é destacado no texto alguns outros termos não mencionados na Tabela 1 , mas bastante peculiares. 
Os jogos de linguagem ocorrem quando os conceitos, que para Dahlberg (1978) são unidades do conhecimento, assumem usos e características distintas. Um bom exemplo sobre a questão dos jogos de linguagem, em relação à Arca do Gosto e os problemas conceituais que podem ocorrer em sistemas de organização do conhecimento, quando não é dada a devida atenção ao uso de ontologias, taxonomias e tesauros, é o caso do bacuri - alimento presente na Arca, registrado como integrante da divisão da região centro-oeste brasileiro (ver Tabela I).

Bacuri é um nome popular dado a dois frutos diferentes: o Platonia insignis e o Scheelea phalerata. O primeiro é um fruto de contorno arredondado, caroço grande, envolto em delicada polpa branca. O segundo possui formato de coquinho, com polpa alaranjada e com a presença de uma amêndoa rica em óleo em seu interior, sendo um dos principais alimentos da arara-azul - espécie de ave típica da floresta amazônica, cerrado e pantanal sul-americano. Enquanto o primeiro fruto brota em cabinho nos galhos de uma árvore frondosa, o segundo nasce em uma palmeira, em cacho. Ambos os frutos são comuns nas regiões centro-oeste, norte e nordeste, o que acentua ainda mais as confusões em relação à caracterização do fruto em função da variação linguística de seu nome.

Ao analisarmos o Catálogo A Arca do Gosto no Brasil, a descrição do bacuri faz menção ao fruto da palmeira. Contudo, a ilustração de referência, presente no catálogo, remete ao fruto da árvore. Já na versão do site do projeto (www.slowfoodbrasil.com), o catálogo apresenta como foto de referência, o fruto da palmeira, dialogando com a descrição de forma exata - o que leva o usuário a entender que o produto selecionado corresponde, de fato, à imagem fornecida. Entretanto, ressaltamos que na descrição do fruto no catálogo, há ainda uma inconsistência de informação em relação ao trecho a seguir transcrito: "o bacuri é uma das frutas mais populares dos mercados de São Luiz, Teresina e Belém. [...]" (Slow Food, 2017, p. 31). Essa é uma informação que corresponde ao Platonia insignis e não ao Scheelea phalerata, fruto efetivamente registrado no catálogo.

No que diz respeito ao Platonia insignis, importa destacar que esse fruto também costuma ser chamado popularmente por outros nomes, além de bacuri, como landirana, pacuri, entre outros nomes não registrados. Já a Scheelea phalerata, nome científico citado tanto na versão livro da arca, quanto do site do projeto, é conhecida pelos nomes de acuri, acurizeiro, coqueiro-acuri, ganguri.
Destaca-se que as versões impressas (livro) e digital (site) do catálogo, ainda ressaltam a existência de alguns outros nomes pelos quais os alimentos são conhecidos. Porém, a configuração do catálogo e mesmo o apontamento desses nomes não levam em consideração bases utilizadas em estudos como ontologias, taxonomias e tesauros. Consequentemente, não há indícios de levantamento dos nomes mais populares e usuais de cada produto. Muitas vezes, os alimentos são tratados por nomes menos comuns, como é o caso da própria Scheelea phalerata, cujo nome mais popular, sobretudo na região centro-oeste, é acuri.

Assim, o caso do bacuri é um exemplo de jogo de linguagem no qual um mesmo nome pode se referir a alimentos diferentes, de acordo com as variações culturais que a linguagem assume dentro de uma mesma língua e território nacional.

Além disso, ao constatar que as diferentes versões do catálogo apresentam estruturas e conteúdos distintos, foi possível perceber, também, a compreensão dos conceitos abordados e constatar a existência de jogos de linguagem por trás dos nomes dos produtos.

Em relação à versão impressa do catálogo Arca do Gosto sobre o Brasil, além do bacuri, destacase aqui alguns outros produtos alimentares elencados na Tabela 1 , ao final deste artigo. Tais produtos apresentam jogos de linguagem que comumente levam a sérios problemas de compreensão. São eles: (1) o arroz-nativo-do-pantanal, que costuma ser facilmente confundido com o arroz vermelho, sendo comum que ambos sejam chamados de arroz vermelho "por conta de terem uma coloração muito parecida" (Fonseca; Troitiño, p.238, 2021); (2) o ora-pro-nóbis, que também é conhecido como jumbeba, este último nome também atribuído ao fruto mais conhecido como jurubeba; (3) o cambuí (nome científico Myrciaria Tenella (DC. O. Berg), sendo o nome popular desse fruto utilizado também para fazer referência tanto à maria- preta, quanto à pimenta rosa, por vezes ocasionando confusão no momento da identificação terminológica dos frutos.

No que diz respeito à existência de diversos nomes para um mesmo alimento na Arca do Gosto brasileira, a semelhança do já relatado a respeito do bacuri, pode ser citado como exemplo, outros alimentos da arca que não foram selecionados para compor a Tabela I, mas que são igualmente complexos em relação à sua nominação: o melão-coalhada; o assa-peixe; e da bocaiúva são alguns possíveis exemplos, entre outros. No livro A Arca do Gosto no Brasil (Slow Food, 2017) é possível constatar como sendo outros nomes do 
melão-coalhada, o melão-da-terra e o melão-pepino. Já a bocaiuva também pode ser chamada de macaúba, coco-baboso, enquanto o assapeixe possui nomes como cambará-branco, chamarrita, mata-pasto e enxuga. É interessante lembrar aqui que, para Michèle Hudon (1997), as línguas refletem como as pessoas enxergam e interagem com o mundo.

Ainda a respeito das variações de linguagem na Arca do Gosto, é algo que vai além de diferenças causadas pela diversidade cultural ou regionalismos, visto que em alguns casos, também pode consistir na distinção de variedades da mesma espécie, como é o caso da gabiroba-rugosa e guavira, elencadas na versão do catálogo do site. Enquanto a primeira se refere a uma variedade daquela espécie, a segunda abarca todas as variedades da espécie, a qual também são conhecidas apenas por gabiroba, entre outros nomes.

É muito importante compreender as questões que dão origem a essas variáveis para pensá-las no âmbito dos sistemas, pois conforme Rodrigo Lima e Giovana Maimone (2017), os sistemas de organização do conhecimento são circunstanciais. Pensando nisso, a informação contida nesses sistemas deve ser entendida diante de suas premissas de uso, pois seus significados podem variar em decorrência deles.

Os jogos de linguagem proporcionam reflexão a respeito da ambiguidade de sentidos que, por vezes, ocorrem na atribuição de nome aos diversos produtos de nossa cultura - em especial os alimentos - demonstrando o quanto o fator cultural é importante na construção da linguagem e da língua, e que este não tem como influência apenas o território ou regionalismos, mas todo um contexto, vivência e um complexo de fatores. Tomemos o exemplo de Wittgenstein (2012). Para o autor, a interpretação da linguagem é algo subjetivo, de modo que estabelecer que o significado que se tem de algo é o mesmo que se julga ter é uma atitude equivocada, pois é comum que se aprenda usos diferentes da mesma palavra.

O pensamento de Ludwig Wittgenstein traz uma interessante reflexão a respeito do modo como a linguagem se molda às diferentes perspectivas $e$ contextos. Os exemplos do autor servem de analogia para explicar o que ocorre quando um sistema de informação não evidencia adequadamente os diferentes nomes atribuídos a um mesmo objeto. Nesse sentido, o catálogo Arca do Gosto torna-se um interessante exemplo, posto ser possível encontrar entre seus registros exemplos de variações linguísticas existentes, utilizadas para fazer menção a um mesmo alimento, assim como exemplos de diferentes alimentos identificados por um mesmo nome.
Saldanha (2014), lembra que para Wittgenstein, o conhecimento é constituído por um infinito de contextos e contextualizações, visto que de acordo com o domínio em que este se insere, pode vir a assumir distintas características, considerando que cada grupo possui sua própria perspectiva de representação do mundo.

Nesse sentido, em relação aos jogos de linguagem presentes no catálogo Arca do Gosto brasileiro, como apresentado, pontua-se que a análise de domínio serve como instrumento de elucidação da riqueza cultural de um país e de distinção da relevância de cada alimento em sua biodiversidade, bem como seu destaque. Afinal, como explica Tennis (2012, p. 7) é esperado que "toda análise de domínio possua uma seção de definições, escopo e alcance, e propósito". Assim, na concepção aqui apresentada, o emprego da análise de domínio se justifica por sua pertinência metodológica, pois traz em suas bases as referências necessárias e que são foco para um exame do catálogo Arca do Gosto, a partir da perspectiva da Organização do Conhecimento. Aliás, o próprio catálogo Arca do Gosto se trata de um domínio.

Assim, a Organização do Conhecimento se faz extremamente necessária aos sistemas de organização. Catalogar produtos alimentares, no sentido por este estudo constatado, sem antes averiguar conceitos e conteúdos, pode trazer prejuízos a estrutura do sistema no qual estão inseridos, além de prejudicar sua intenção final, que é informativa.

\section{Considerações finais}

Os jogos de linguagem estão por toda parte, fazemos uso deles o tempo todo, e não seria diferente na atribuição de nome aos alimentos. A linguagem está estreitamente relacionada ao fator cultural, assumindo, assim, variações conforme o contexto em que se insere. Conforme Garcia Gutiérrez (2008), é na interação que reside o sentido.

Quando Ludwig Wittgenstein afirma que se deve assumir postura pragmática em relação aos usos da linguagem, a orientação cabe tanto em relação à construção dos sistemas de organização do conhecimento, pensando na compreensão dos conceitos nele tratados, quanto na busca por esses conceitos.

O estudo aqui apresentado, constatou que o contexto por trás dos jogos de linguagem pode influenciar na definição dos conceitos. Assim, a proposta elaborada por Ludwig Wittgenstein, se apresentou como um interessante viés interpretativo por proporcionar a compreensão de que o 
fato de um mesmo alimento receber nomes iguais ou diferentes, em contextos distintos, se reflete nos sistemas de organização do conhecimento. Não por ocasionar erros, muito pelo contrário, por ser capaz de mencionar essas variações os sistemas se tornam mais ricos e menos passíveis de erro, no que tange à transmissão dos conceitos tratados. Em síntese, contribui com a construção do conhecimento.

Em si, a linguagem é algo mutável, em interação constante com o tempo e espaço no qual está se inserida. Daí a importância das taxonomias, tesauros e ontologias nos sistemas de organização do conhecimento. No caso específico da Arca do Gosto, é importante lembrar que essas ferramentas se fazem ainda mais necessárias por se trata de um sistema construído a partir de colaboração coletiva (Fonseca e Troitiño, 2020, p. 200):

É preciso ter cautela, pois qualquer pessoa pode contribuir com informações sobre produtos que tem potencial para estar na Arca do Gosto, e se não houver monitoramento atento nessa troca entre os saberes tradicionais e o científico, tal desequilíbrio pode acarretar prejuízos à Organização do Conhecimento processado pelo mesmo, correndo o risco de que informações errôneas ou inconsistências façam parte dessa sistematização.

Enfim, do ponto de vista da Organização do Conhecimento, as inconcretudes do catálogo Arca do Gosto, em relação à contextualização de alguns alimentos entre os nomes a eles atribuídos e seu conceito, conforme aqui demonstrado, representa o quanto os usos linguísticos sobre um conceito são importantes para os sistemas de organização do conhecimento. Mas, principalmente, o quanto ao campo da Organização do Conhecimento pode trazer benefícios para o saber sobre determinada realidade humana.

No caso da Arca do Gosto, seu estudo envolve o levantamento de cada produto indicado e seu detalhamento, com especial atenção aos conceitos que estes representam, variações nominais e usos assumidos, de acordo com a região geográfica, tempo e contexto de produção e uso, dessa forma demonstrando a estreita relação existente entre linguagem e Organização do Conhecimento, com destaque para a importância da Organização do Conhecimento como forma de sanar inconsistências interpretativas que podem ocorrer em sistemas de organização do conhecimento, em função da existência de jogos de linguagem.

É igualmente importante destacar que a Organização do Conhecimento, no âmbito do catálogo Arca do Gosto, ao contribuir para que seja possível resolver problemas de comunicação advindos da existência de jogos de linguagem, desempenha um importante papel social ao permitir que se conheça, valorize e preserve a cultura alimentar local.

\section{Referencias}

Condé, Mauro Lúcio Leitão (1998). Wittgenstein: linguagem e mundo. São Paulo: Annablume.

Dahlberg, Ingetraut (1978). Teoria do conceito. Ciência Da Informação.7:2. http://revista.ibict.br/ciinf/article/view/115 (2021-01).

Fonseca, Gabrieli Aparecida da; Troitiño, Sonia (2020). A dimensão social do catálogo Arca do Gosto no Brasil enquanto serviço de informação e sua relação com a organização do conhecimento. // Tramullas, Jésus; GarridoPicazo, Piedad; Marco-Cuenca, Gonzalo (eds.) Actas del IV Con-greso ISKO España y Portugal 2019, 197-203.

Fonseca, Gabrieli Aparecida da; Troitiño, Sonia (2021). A importância da Organização do Conhecimento para a disseminação de políticas públicas: uma análise comparativa entre o catálogo Arca do Gosto, Guia alimentar para a população brasileira e livro alimentos regionais brasileiros. // María-Jesús Colmenero-Ruiz; et al. Pesquisa em gestão e organização da informação: panorama hispanobrasileira. São Paulo: ECA -USP.

García Gutiérrez, Antonio (2008). Outra memória é possível: estratégias descolonizadoras do arquivo mundial. Petrópolis: Vozes.

García Gutiérrez, Antonio (2011). Pensar en la transcultura. Madrid: Plaza e Valdés Editores.

García Marco, Francisco Javier (2021). La organización del conocimiento al servicio de la interconexión entre las instituciones de la memoria y el turismo cultural. // Scire. 27:1, 55-70. https://www.ibersid.eu/ojs/index.php/scire/ article/view/4780/4287 (2021-01).

Hjorland, Birger; Albrechtsen, Hanna (1995). Toward a new horizon in Information Science: domain-analysis. // Journal of the American Society for Information Science. 6: 6, 400-425.

Hjorland, Birger (2008). What is Knowledge Organization (KO)?. // Knowledge Organization, Germany. 35:2/3, 86101.

Hudon, Michèle (1997). Multilingual thesaurus construction: integranting the views of different cultures in one gateway to knowledge and concepts. // Knowledge Organization. 24:2, 84-91.

Irving, John; Ceriani, Silvia (2013). Bem vindos ao nosso mundo: o manual. Slow Food. http://www.slowfoodbrasil.com/documentos/manual-do-slowfood-2013.pdf (2021-03).

Lima; Rodrigo César Castro; Maimone, Giovana Deliberali; (2019). Aspectos da organização do conhecimento segundo alguns parâmetros da obra de Ludwig Wittgenstein. // Encontros Bibli: Revista eletrônica de Biblioteconomia e Ci-ência Da informação. 24,n.55, 1-17.

Makuta, Glenn (2018). Biodiversidade, Arca do Gosto e Fortalezas Slow Food: um guia para entender o que são, como se relacionam com o que comemos e como podemos apoiá-las. São Paulo: Associação Slow Food do Brasil. https://slowfoodbrasil.org/2018/02/biodiversidadearca-do-gosto-e-fortalezas/ (2021-03).

Milano, Serena; et. al (2013). A Arca do Gosto Como criar o maior catálogo de sabores do mundo: um patrimônio para descobrir e salvar. Roreto di Cherasco:Stampatello. https://slowfoodbrasil.org/wp-con-tent/uploads/2018/02/ slowfoodbrasil.com_documentos_slowfood-publicacao. pdf (2080-07). 
Saldanha, Gustavo Silva (2014). The Philosophy of Language and Knowledge Organization in the 1930s. // Knowledge Organization. 41:4, 996-303. https://www.nomos-elibrary.de/10.5771/0943-7444-2014-4-296/the-philosophyof-language-and-knowledge-organization-in-the-1930spragmatics-of-wittgenstein-and-ranganathan-volume-412014-issue-4 (2021-01).

Slow Food (2017). A Arca do Gosto no Brasil: Alimentos, conhecimentos e histórias do patrimônio gastronômico. Bra: Slow Food. https://www.fondazioneslowfood.com/ wp-content/uploads/2017/10/ADG_Brasil_digital_b.pdf (2021-03)

Slow Food Internacional; Fundo Internacional de Desenvolvimento Agrícola (2015). Comida com gosto de licuri: receitas. Bahia: COOPES Cooperativa de Produção da
Região do Piemonte da Diamantina. http://slowfoodbrasil.com/documentos/licurilivro-de-receitas.pdf

Tennis, Joseph (2012). Com o que uma análise de domínio se parece no tocante a sua forma, função e gênero?. II BJIS. 6:1, 3-15. https://revistas.marilia.unesp.br/index.ph p/bjis/article/download/3026/2301/10132 (2021-01).

Wittgenstein, Ludwig (2012). Livro azul. Trad. Ronai Rocha. https://pt.scribd.com/document/333579985/WittgensteinO-Livro-Azul-pdf (2021-03).

Enviado: 2021-04-02. Segunda versión: 2021-07-10. Aceptado: 2021-09-22. 